\title{
Developing a Conceptual Framework of Skills Immigration in South Africa
}

\author{
CJ Botha Prof \\ Associate Professor, North-West University, Potchefstroom, South Africa, 2520 \\ Email: christoff.botha@nwu.ac.za \\ F Rasool Dr
}

PhD Graduate, North-West University, Potchefstroom, South Africa, 2520

Email: fathimarasool22@gmail.com

\section{Doi:10.5901/mjss.2014.v5n20p62}

\section{Abstract}

South Africa is in the throes of a skills crisis. This situation is seriously hampering the country's economic progress and global participation. This study focuses on the analysis of skills migration in South Africa, and specifically aims to provide a conceptual framework for better cognition of the skills situation in South Africa. This crisis is largely due to the failure of the national education and training system to supply the economy with much needed skills required to support economic growth and job creation. The findings of this study indicated that there are various factors that are contributing to the skills shortages in the country. Some of the factors include: poor education standards, emigration, crime and HIV. It must be noted that these factors cannot be addressed overnight. Hence, this paper emphasised the role that skilled foreign workers can play in alleviating the skills shortages in the country. The contribution of foreign workers could be viewed as a short to medium solution to the skills crisis. Finally, this study has confirmed the findings of similar studies undertaken by the Centre for Development and Enterprise that opening the doors to high-skilled immigration can only serve as a means of supplementing the skills pool and hence contributing to the economic growth of the country.

Keywords: Emigration, immigration, migration, skills, and globalization

\section{Introduction}

The migration of skilled labour across national boundaries and continents is a growing trend fuelled primarily by globalisation and technological advancements. Blain (2013:2) indicates that Asia today is facing serious skills crises. This development is creating huge global labour market imbalances with developing countries experiencing growing levels of skills shortages and an ever-increasing threat of skills flight (Maharaj, 2004:2). These countries are losing skills to developed countries in North America, Western Europe and Australasia who possess robust skills immigration regimes (Bisseker et al., 2005:19; Crush et al., 2000:10 \& Rodrik, 2006:4).

Developing nations are responding to this flight of skilled labour in various ways (Blain, 2013:4). Some measures include expansion of national education and training systems, increased investments in vocational education and training, reviewing industrial policy to increase growth and reduce unemployment, tax incentives and attractive immigration policies to lure skilled labour to a country (Blain, 2013: 5, Kraak, 2008:7; CDE, 2007:11; JIPSA, 2006:1 \& DOE, 2005:15).

Historically, the benefits of skilled immigration have been greatly valued by developed countries. They regularly recruit engineers, doctors, teachers and nurses to their countries. For instance, Singapore, USA, Germany and Ireland have turned to India to recruit information technology engineers, while the United Kingdom has programmes to attract nurses (Bernstein, 2000:4). These countries see migration as one means of alleviating labour market shortages (OECD, 2003:103).

South Africa is also a victim of skills emigration. Common South African destinations for the flight of skilled labour include the United Kingdom, United States, Canada, Australia, New Zealand and the United Arab Emirates. This "brain drain" is proving to be a major impediment to economic growth, social stability and job creation. Although the country's skills shortages are largely the product of a poor education and training system, skills emigration is exacerbating the problem (Rodrik, 2006:3-5; Bernstein, 2000:4; \& Crush et al., 2000:2).

One of the government's policy initiatives for growth, the Accelerated and Shared Growth Initiative for South Africa (ASGISA, 2006:1-7), identifies skills shortages as a binding constraint for economic growth. Concern over this issue and 
the failure of the national education and training system to supply the economy with much needed skills is leading to a debate about creating a pro-skills immigration policy regime to support economic growth and job creation. OECD (2013:2) shows that education in South Africa is a critical problem. Skill mismatches represent one aspect of the persistently high unemployment rate.

\section{Literature Review}

This section focus on the conceptual definitions of Emigration, Immigration, Migration, Brain drain, globalisation, pushand pull factors and skills shortages. It concludes with a literature review for skills immigration in South Africa.

\subsection{Conceptual Definitions}

Emigration: to leave one's country of normal residence and settle permanently in another country (Scruton, 1982:144).

Immigration: the movement of a person to another country with the intention of making it one's permanent residence (Du Preez, 2002:80).

Migration: means to travel so as to change one's place of residence. It also includes moving to another area in order to seek better living conditions (Du Preez, 2002:80). Thus, the term includes both immigration and emigration (Oxford English Dictionary Online, 2009).

Brain drain: a permanent or temporary loss of skilled or professional people belonging to various fields which are vital to the functioning of the country (McDonald \& Crush, 2002:6).

Globalisation: refers to increased cross-border trade, liberalisation and advances in information technology with the intention of creating a borderless world economy (Scholte, 1997:431).

Push factors: factors that drive people out of their home countries due to their unhappiness with the situation in the country (Mattes \& Richmond, 2000:28)

Pull factors: factors that draw people into a country due to lucrative job offers or to conditions that are better than their home-country (Rogerson \& Rogerson, 2000:47-48).

Skills shortage: "a skills shortage occurs when any one of the following situations arises or a combination of them: shortage of workers in a particular occupation, labour demand exceeds availability of skills, or workers lack appropriate qualifications" (Barnow et al., 1998:59; Shah \& Burke, 2005:44 \& Trendle, 2008:4).

\subsection{Skills immigration in South Africa}

The issue of skills shortages presently is receiving considerable attention in South Africa. Facchini, Mayda \& Mendola (2013:22) indicates how immigration is becoming more and more important for the country. There appears to be a general consensus that the South African labour market is characterised by a skills mismatch with large numbers of unemployable people, including graduates, and concomitant large numbers of job vacancies (Kraak, 2008:1; Bissekar \& Paton, 2005:18-20; Rodrik, 2006:3; and Hausmann, 2007:66).

\subsubsection{The Labour Market}

The labour market, in line with international trends, is witnessing a significant decline in the relative demand for low skilled labour, particularly in mining, agriculture and manufacturing which constitute the least skills intensive parts of the economy (Rodrik, 2006:4). For example, in 2004 mining employment was 29\% lower than in 1994 and $43 \%$ below its historical peak in 1986, a loss of 177261 and 323603 jobs respectively. Agriculture lost 112352 jobs between 1994 and 2004 , a fall of $12.1 \%$. During the decade between 1994 and 2004, manufacturing jobs fell by $11.7 \%$ or 165448 jobs and by 21.0 percent or 332441 jobs since its 1982 peak (Hausmann, 2007:75).

In contrast, the labour shortages are prevalent at the intermediate and upper-end of the skills spectrum, particularly in the financial and services sectors which have recorded steady growth in recent years. This pattern is aggravating the impact of the skills constraint on the economy (JIPSA, 2006:4). According to Bhorat (2013:22) the biggest challenge is to fix the basic education system and, further, to expand post-school training opportunities in colleges and universities 
In addition, skills migration is also contributing to skills shortages in South Africa. The country is losing artisans, technicians, doctors, nurses, teachers and accountants in increasing numbers. A recent study found that $40 \%$ of skilled South Africans are considering emigrating across all race groups. In 2000 the comparative number was a mere 18\% (Bissekar et al., 2005:18-20). Therefore South Africa, like other countries, is concerned about skills emigration.

According to the Centre for Enterprise Development (CDE, 2007:17), population pyramids between 1995 and 2005 reveal that there is large-scale emigration of whites between the ages of 25 and 34 years, the most economically active and skilled group. This is supported by figures from receiving countries such as United Kingdom and Australia confirming large-scale emigration from South Africa for the period has taken place (CDE, 2007:17).

\subsubsection{Push factors}

The reasons cited are varied. Push factors include employment equity, crime, political instability, declining educational standards and power outages. Pull factors include attractive salaries and working conditions, promotional opportunities, safer living environment and better education.

The education and training system's failure to produce sufficient number of graduates is viewed as a primary reason for modest growth rates in recent years (Kraak, 2008:17; Hausmann, 2007:79 \& JIPSA, 2006:9). According to the Department of Education (DOE) (2005:18), 50\% of university students, $32 \%$ of technikon students and $9 \%$ of distance education students who had enrolled for studies in 2000 did not complete their degrees in the 5 years between 2000 and 2004. This represents a huge dropout factor, with $38 \%$ of university students, $58 \%$ of technikon students and $71 \%$ of distance education students leaving these institutions in this period. The report also found that the supply of skills has flattened out and in some areas even fallen from levels in the late 1990s (DOE, 2005:21).

The country is experiencing an average loss of more than 4000 skilled people a year. This is disguised by serious data deficiencies. There is a shortage of skilled managers and experienced professionals in almost all sectors (Bernstein, 2000:6). Hence, concern about skills shortages has led to renewed calls to establish a more competitive skills immigration regime in the global race to attract talent. According to one business institute, South Africa's skills shortage is so critical, that the country should allow entry of any skilled person who wishes to enter (Crush et al., 2000:2).

One of the key recommendations of the Harvard Group, an international advisory panel appointed by National Treasury to identify binding constraints in the economy and propose growth strategies, is to encourage immigration of highly skilled people to ease skills shortages (Hausmann, 2007:101). The Harvard Group is of the view that encouraging the retention of all high skilled South Africans and the attraction of foreign high skilled persons will be crucial to limit wage inequality and facilitate the creation of jobs for the less skilled and thus achieve shared growth.

One of the major criticisms levelled at government is at the level of immigration policy. It is argued that our policy is characterised by an irrelevant and unworkable quota permit system with its reliance on unrealistic enumeration and restrictive definitions of scarce skills (CDE, 2007:5).

According to the Centre for Development and Enterprise (2007a:3), South Africa needs a well-managed immigration policy that seeks human capital in much wider senses than restrictive categories of elite priority skills. Immigration policies should be built into a long-term plan for growth and job creation. South Africa's immigration policy should be revised if the country wants to benefit from migrants (Taylor, 2009:4).

\section{Research Methodology}

The research methods used includes an extensive literature study on the specific topic related to this paper, and an empirical study (survey research). Quantitative statistical analysis was employed to analyse the data.

\subsection{Empirical study}

Survey research was employed in order to determine the effectiveness of South Africa's immigration policy with regard to skills requirements. A questionnaire was used to obtain information from a sample of organisations and businesses who are actively involved in recruiting skilled foreign labour.

\subsection{Research design}

A survey-based research design was adopted for this paper as it allowed for the gathering of data from a relatively large number of cases at a particular time. It uses distinct methods of data collection with a special form of data analysis by 
statistical means. It is not concerned with the characteristics of individuals as individuals. Rather, it is concerned with the generalised statistics that result when the data is abstracted from a number of individual cases (Best \& Khan, 1986:106; Field, 2009:4).

The survey method requires expert and imaginative planning, careful analysis and interpretation of data gathered and the logical and skilful reporting of findings (Seaman, 1987:214).

\subsection{Research instrument}

A closed questionnaire was drafted from the concepts, classifications and different measuring items that were discussed in the literature review. The questionnaire was used to determine the effectiveness of South Africa's immigration policy with respect to skills immigration. It was e-mailed or posted to various organisations. In this form of data gathering, participants are more willing to be honest as their anonymity is assured (Salkind, 2007:138). The questionnaire posed immigration issues on a five-point Likert scale.

\subsection{Sample population}

It was decided to use a sample of 800 organisations/businesses that seek to employ skilled foreign labour in South Africa. This sample was determined after contacting several organisations/businesses either electronically or by telephone to determine whether they employ skilled foreign labour. Further, it was ensured that the respondents belong to various organisations. Hence, the selection of the respondents was done by means of stratified random sampling. This method is primarily used to ensure that different groups of a population are adequately represented in the sample so that the level of accuracy is increased (Babbie, 2010:426).

\subsection{Data collection}

The mailed questionnaire, a self-completion method of collecting of information, was used to gather data for this study. Three weeks after the initial mailing of the questionnaires, a follow-up letter was dispatched to the various organisations which had not responded. A week later a telephonic follow-up was done. By the due date when the researcher proposed finalising the computation of the information, a total of 306 questionnaires had been received from an initial 800 questionnaires that were mailed. This represented a satisfactory response rate of $38.1 \%$. There was a non-response of 494 questionnaires, representing $61.75 \%$ of the sample. This outcome is represented in figure 1.1 below. Perhaps this response rate could have been maximised if there was the use of incentives.

Nevertheless, the mailed questionnaire was the only feasible approach for this research as this choice of method was prompted by the wide geographical spread of the population and financial constraints.

\subsection{Statistical analysis}

Quantitative analysis was used to analyse the data for all the articles. The statistical analysis for this research was performed by using the Statistical Package for the Social Sciences (SPSS). A range of calculations were undertaken in order to ensure that the data analysis was effective (Du Plessis, 2009:27).

In order to determine the reliability of the collected data, Cronbach alpha coefficients were calculated for each factor. This is one method of estimating the reliability and internal consistency among the items. Cronbach alpha values of 0.70 are deemed to be satisfactory (Field, 2009:666).

Finally, the data was subjected to a factor analysis in order to confirm the constructs that had been identified from the literature (such as the Immigration policy, the Immigration procedures and the Push and Pull factors). Factor analysis was also used when these constructs did not confirm as single entity, to identify the underlying entities or sub factors within. The factor analysis also purified the statements from the measuring instrument by identifying the less important statements that could be deleted. The Varimax rotational method was used as it maximises the variance explained by factors if there is a low correlation coefficient between the factors (Du Plessis, 2010; Field, 2009:749). Finally, the factor analysis provided the variance explained of each construct as an indicator of relative importance (Field, 2009:667).

\section{Findings and Discussion}

The following figure (Fig 1) provides a comprehensive view of factors that contribute to the skills immigration debate. The 
results of the research are used to provide a conceptual framework for skills immigration in South Africa.

\subsection{Skills immigration policy}

The skills immigration policy of the country was analysed and a total of four factors are linked to it. These factors are:

- South Africa's Immigration Policy;

- South Africa's Immigration Procedures which further included three sub factors, namely: unfriendly immigration procedures, quota-based immigration procedures and attitudes towards fixed-based permits;

- The Department of Home-Affairs (DHA); and

- In- Company Immigration

It is evident from the explained variance of each factor that companies that employ skilled foreign labour encounter major obstacles in their recruitment process. This is largely due to the following realities: firstly, the immigration policy is restrictive and unclear. The procedures in implementing the policy is highly problematic in that the quota work permits are very restrictive and also the time frame in processing work permits is too long. Secondly, the standard of service provided by the DHA, is largely inadequate. Thus, this makes in-company recruitment of skilled foreign workers highly problematic. The high cumulative variance of the above factors which ranges from $65.6 \%$ to $76.4 \%$ confirms the preceding findings. It therefore indicates that the efforts of these organisations are being frustrated by the restrictive skills immigration policy of the country.

\subsection{Push and pull factors}

This section identified two factors that are linked to the skills immigration policy of the country, namely:

- Push Factors which included four sub factors, namely: employment issues, national policies, standards of living, impact of quality of life and work opportunities; and

- Pull Factors which included three sub factors, namely: quality of work life, work opportunities and quality of family life.

The push and pull factors are also linked to skills immigration. Many skilled workers are leaving the country due to the factors mentioned above. These factors are contributing to the extensive loss of skills in the country. The cumulative variance of $70,2 \%$ and $70,9 \%$ confirms these findings. Importing of skills is recognised as one solution to this problem. However, this is not as simple as it appears due to the restrictive skills immigration policy.

\subsection{View of skills immigration}

This section includes only one factor that is linked to the skills immigration policy of the country, namely:

- Views on skills immigration. The factor includes three sub factors, namely: skills immigration as a form of contribution to the economy, acceptance of skilled immigrants and benefits of skilled immigrants.

The results of the empirical study with regards to the above issue indicate that there should be an acceptance of skilled workers. The public should be educated on the contribution of skilled foreign workers. Further, these workers should be afforded the same treatment as the citizens of the country due to the contributions they offer. The high cumulative variance of $73.9 \%$ gives support to this argument. As evidenced in the study, skilled foreign workers do not take the jobs of the locals but rather they create more employment opportunities. They also pass their skills to locals. Skilled foreign workers are also no burden to the social services of the country.

\subsection{Suggested approach for improvement}

Section $D$ is represented by one factor that is linked to the skills immigration policy of the country. This factor and its sub factors are:

- Suggested approach to improve skills immigration which included three sub factors, namely: positive awareness of skilled immigrants, positive approach to skilled immigrants and social and public awareness campaign.

Due to global skills shortages there is growing competition among countries to attract skilled immigrants. Many countries have targeted skilled immigration programmes to attract the skilled immigrants from all over the world to improve their competitive footing in the global economy. These countries have seen the benefits of highly skilled 
immigrants in their countries. South Africa can learn from such countries and create an increased social and public awareness campaign of the positive role that skilled immigrants can make in the country. This will thus make the recruitment process easy. The results of the empirical study indicate that the respondents are in full support of such a campaign. The high cumulative variance of $73.4 \%$ also gives support to this argument.

\subsection{Proposition}

One factor is linked to the skills immigration policy of the country in this section, namely:

- Skills immigration policy propositions which included three sub factors, namely: quality of skilled immigrants, stringent control on skilled immigrants and skills based entrance.

South Africa appears to lack the ability to attract skilled immigrants. The central problem appears to be a restrictive immigration policy that imposes penalties and impediments on employers who source skilled foreigners. Further, it is highly restrictive, bureaucratic, user-unfriendly and costly to administer. Moreover, it serves as an impediment for business and industry to recruit skilled foreign labour into the country as a result of excessive, and often, unnecessary regulations and procedures. Thus, this policy is detrimental to South Africa's competitiveness in the global economy and deters investors from utilising skills not available in the domestic labour market. Hence, there is a general consensus that South Africa's policy on skills immigration is in need of radical review. The cumulative variance of $69.3 \%$ confirms the restrictive nature of the skills immigration policy.

From the above, it is evident that there are various factors that revolve around the skills immigration debate of the country. However, the value of the study is that it not only identified and confirmed the different factors; it also adds relative importance to each of the factors and its sub factors. Figure 1 shows all these factors and their sub factors as an integrated map of skills migration.

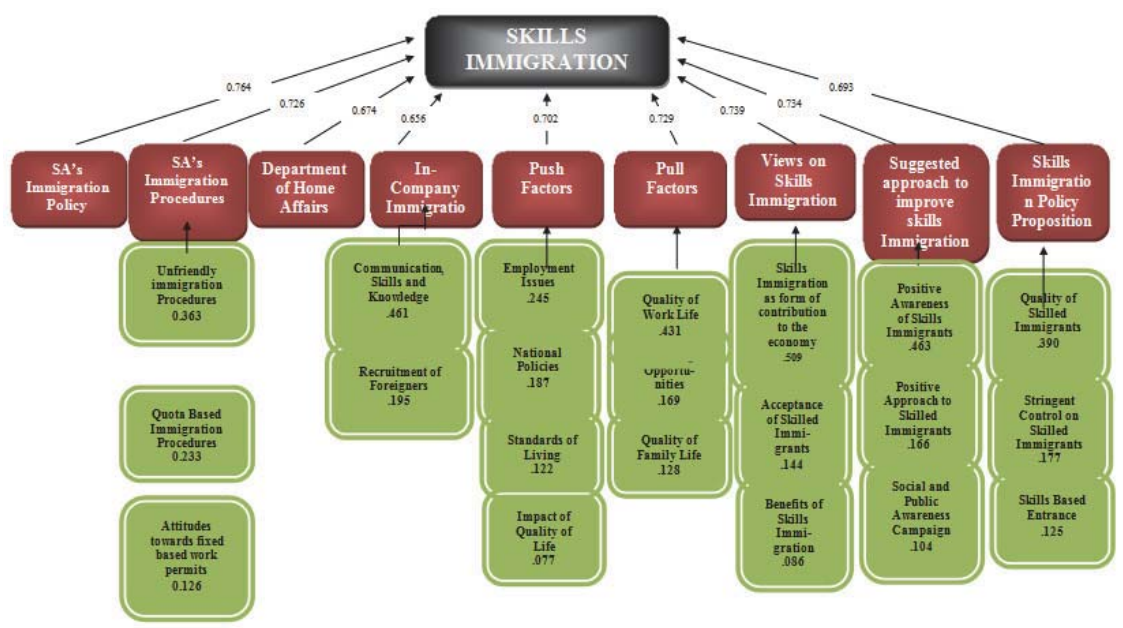

Figure 1: Conceptual Framework of Skills Migration in South Africa

\section{Conclusion}

The use of the literature to aid in the construction of a research instrument proved invaluable. Not only did the literature review provide sound directions on the structure of the questionnaire, it also identified various items that needed to be measured. It is concluded that the use of theory is imperative in constructing a questionnaire for the empirical research.

The statistical analysis revealed that the identified constructs such as Immigration policy, Immigration procedures, Push and Pull factors and others could be validated. The factor analysis either confirmed the construct and its measuring items, or identified sub-factors within the construct. In all cases relative importance was calculated (variance explained and factor loadings), while reliability (Cronbach alpha), suitability for multivariate analysis (Bartlett) and sample adequacy (KMO) added to conclude that the research instrument compiled from the literature provided a valid questionnaire. 
Cronbach alpha coefficients were calculated for each factor. The results indicated that there was a high degree of reliability and internal consistency among the items. This implies that the results were not only valid but that it would be appropriate to use this test in similar studies undertaken.

The Kaiser-Meyer-Olkin (KMO) measure of sampling adequacy proved that the variables in this study were strong enough to proceed with a factor analysis. The large KMO values in this study indicated that the sample size was appropriate as the factor analysis for this particular sample size was reliable. The KMO test confirmed the adequacy of the sample, hence the validity of the results.

The Bartlett test of sphericity was also appropriate for this study as it yielded p-values smaller than 0.0001 . This indicated that the correlation between the variables was sufficient for factor analysis.

It is concluded that the questionnaire and the data are reliable and valid.

The population, the sample selected and the eventual gathering of the data for this research in the form of survey research was also effective. The data collection allowed for the collection of data from a wide geographical spread of the population. It also allowed for the gathering of data from a relatively large number of cases at a particular time. This made it cost effective and was also not time consuming. In addition the sample was also statistically proven to be adequate by the $\mathrm{KMO}$ analysis. It is thus concluded that this method of data gathering methodology is successful within the mentioned constraints.

It is confirmed from the results that skills immigration in South Africa consists of nine constructs). All nine these constructs are important since they all have proportional values (between 0.65 and 0.77 ) which indicate their influence on skills migration per se. None of the constructs have low values. It is thus concluded that all these constructs are important in understanding and addressing skills migration in South Africa

Within these nine constructs, six have sub-factors to deal with. The values relative of these sub-factors as contributors to the factors (or constructs) are also important as it also indicates their relative importance to skills immigration (albeit through the construct it resides within). It is thus concluded that these sub-factors are also important indicators of skills immigration in South Africa.

Almost all the constructs and the sub-factors (where present) are reliable and should represent itself in similar studies on skills immigration. There are only two sub-factors with low reliability coefficients. It is thus concluded that, apart from the two factors, the results obtained from the analysis could be regarded as reliable.

The core of the research, as summarised by figure 1 above, provides a perceptual map by means of the newly created conceptual framework on skills immigration. It is thus finally concluded that the conceptual framework is a valuable tool in understanding and conceptualising the concept of skills immigration in South Africa.

\section{Acknowlegment}

This research stems from research done by Dr F Rasool as part of her PhD studies at North West University, Potchefstroom Business School.

\section{References}

Asgisa. (2006). A catalyst for accelerated and shared growth - South Africa (ASGISA) Pretoria: Office of the Presidency. [Online] Available http://www.pmg.org.za/briefings/briefings.php?id=246 (February 6, 2006).

Babbie,E.R. (2010). The practice of social research. Belmont. Wadsworth.

Barnow, S., Trutko, J. \& Robert, L. (1998). Skill mismatches and worker shortages: the problem and appropriate responses. Urban Institute Policy Memorandum prepared for the U.S. Washington DC: Department of Labor.

Bernstein, A. (2000). Why is South Africa afraid of skilled immigration when they are essential for enhancing economic growth? Acumen, October.

Best, J.W. \& Khan, J.V. (1986). Research in education. Englewood Cliffs: Prentice-Hall.

Bhorat, H., Hirsch, A., Kanbur, R. \& Ncube, M. 2013. Economic Policy in South Africa Past, Present, and Future. [Online] Available http://www.kanbur.dyson.cornell.edu/papers/EconomicPolicylnSouthAfrica.pdf. (June 16, 2014).

Blain, J. (2013). Skills shortages in the Asian workplace - Challenges and solutions. [Online] Available http://www.slideshare.net/ JeremyBlain/the-skills-shortages-in-asia (June 16, 2014).

Bisseker, C. \& Paton, C. (2005). No sacred cows. Financial Mail, 29 July, 18-20.

CDE See CENTRE FOR DEVELOPMENT AND ENTERPRISE

CENTRE FOR DEVELOPMENT AND ENTERPRISE. (2007). Skills, growth, and migration policy: overcoming the 'fatal constraint' Pretoria: CDE, November.

Crush, J., Mcdonald, D. \& Williams, V. (2000). Is South Africa losing its minds? Migration Policy Services No. 18. Cape Town: IDASA.

DEPARTMENT OF EDUCATION. (2005). Education statistics in South Africa at a glance in 2004. Pretoria: DOE. 
Du Plessis, T.H. (2009). South African expatriates as potential entrepreneurs: an exploratory study. Thesis submitted for the degree Philosophiae Doctor in Business Management. North-West University.

Du Preez, J. (2002). The depletion of the human resources pool in South Africa. Acta Commercii, 2:80-84.

Facchini,F, Mayda,A.M. \& Mendola, A. (2013) South-South Migration and the Labour Market:Evidence from South Africa. [Online] Available http://ftp.iza.org/dp7362.pdf. (June 16, 2014).

Field, A. (2009). Discovering statistics using SPSS. 2nd ed. London: Sage.

Hausmann, R. (2007). Final recommendations of the international panel of ASGISA, working paper number 161, 08 May 2008, Harvard: Centre for International Development.

JIPSA. (2006). Engineering and intermediate skills acquisition, Technical Working Group meeting, 3 August, Pretoria: JIPSA.

Kraak, A. (2008). The education-economy relationship in South Africa, 2001-2005. Human resources development review. Cape Town: HSRC.

Maharaj, B. (2004). Immigration to post-apartheid SA. Global Migration Perspectives, No.1, June. Global Commission on International Migration. Also available on the web: gcim.org/en/ir_gmp.htmlGlobal\%20Migration\%20Perspectives\%20No\%201.pdf

Mattes, R. \& Richmond, W. (2000). The brain drain: what do skilled South Africans think? Losing our minds: Skills Migration and the South African Brain Drain, (ed.) J Crush, Migration Policy Series No.18, Cape Town: Idasa.

Mcdonald, A.D. \& crush, J. (2002). Destinations unknown: perspectives on the brain drain in Southern Africa. Pretoria: Africa Institute of South Africa.

OECD. (2003). Labour shortages and the need for immigrants: A review of recent studies: trends in international migration, Paris: OECD.

OECD. (2013). OECD Economic Surveys SOUTH AFRICA. [Online] Avalable http://www.oecd.org/eco/surveys/South\%20Africa \%202013\%200verview\%20FINAL.pdf. (June 16, 2014)

Oxford English Dictionary Online. (2010). Oxford University Press. [Online] Availanle: http://dictionary.oed.com/ (September 19, 2009).

Rodrik, D. (2006). Understanding South Africa's economic puzzles. Working paper number 130. August. Harvard: Centre for International Development.

Rogerson, C.M. \& Rogerson, J.M. (2000). Dealing in scarce skills: employer responses to the brain drain. In Crush, J. (Ed.). Losing our minds: skills migration and the South African brain drain. Migration Policy Series No.18. Cape Town: Idasa.

Salkind, J. (2007). Exploring research. 6th ed. Uppersaddle River, N.J.: Pearson.

Scholte, J.A. (1997). Global capitalism and the state. International Affairs, 73(3):427-452.

Scruton, R. (1982). A dictionary of political thought. London: Pan.

Seaman, C.H. (1987). Research methods: principles, practices and theory of nursing. New York: Appleton \& Lange.

Shah, C. \& Burke, G. (2005). Skill shortages: concept measurement and implications. Australian Bulletin of Labour, 31(1):44-71.

Taylor, C. (2009). 'Immigrants can benefit SA if restrictions lifted', The Mercury, 4 February, p4.

Trendle, B. (2008). Skill and labour shortages: definition, cause and implications. Working Paper No.54, Labour Market Research Unit. Queensland: Queensland Government Press. 